\title{
Enhancing the Cross-Cultural Competence of Prospective Language Teachers
}

\author{
Gülşat Bican ${ }^{1, *}$ \\ ${ }^{1}$ Ministry of Education, Ankara, Turkey \\ *Correspondence: Ministry of Education, Ankara, Turkey. E-mail: gulsat.bican@gmail.com
}

Received: March 31, 2021

Accepted: July 12, $2021 \quad$ Online Published: August 17, 2021

doi:10.5430/jct.v10n3p47

URL: https://doi.org/10.5430/jct.v10n3p47

\begin{abstract}
In the twenty-first century, education does not merely focus on information exchange; additionally, it does so on various abilities and living in harmony. To materialize such acquisition among students, cross-cultural competence is an essential vehicle in a rapidly globalizing world. This calls for integrating comprehensive cross-cultural education as an independent subject into teacher training programs alongside the applied practices that go with it. Against this backdrop, the current study aims to determine the cross-cultural competency capabilities of Turkish language teacher candidates studying at one of the major universities in Turkey. In this article, initially cultural dimensions, scope of culture, and aspects of cross-cultural competency are addressed on a theoretical basis. In addition, learning materials are developed by the candidates, based on the instructions provided by the researcher, and analyzed according to their content of cross-cultural competency. The paper also discusses the cultural background of the candidates and their cross-cultural competency capabilities. The findings show that the participants have major difficulty presenting sufficient information or content in developing their cross-cultural competency. In the end, there are recommendations for enhancing the cross-cultural competency capabilities, while shedding light on the inadequate focus devoted to improving these skills within the training programs.
\end{abstract}

Keywords: language teaching, culture, cultural dimensions, cross-cultural competency, cross-cultural education

\section{Introduction}

Today, human mobility among countries and continents is greatly accelerated as a result of globalization and changing living circumstances, leading to cultural diversity to become indispensable for nations hosting immigrants. It becomes even easier for people from different cultures to have interpersonal interactions as technology advances and creates new means of communication. As cultural diversity and contact spread, the concept of cross-cultural competency on a wider scale becomes more visible. In the available research, this concept appears to be wellstudied in the second/foreign language teaching programs or in the context of cultivating communication abilities. Reviewing cross-cultural competency from this perspective assumes that the members of a given culture speaking the same language also share the same beliefs, values, traditions, and customs. However, this does not apply to all situations; for instance, there might be some differences among teens, friends, families, and colleagues in their values, attitudes, and lifestyles despite sharing the same language and culture. Therefore, in the context of language teaching, it is essential to understand the target culture's scope and dimensions besides comparing it with both other local cultures and cross-culturally in order to create a foundation for cultural learning. In this way, one can benefit more from cross-cultural learning. For teaching a target language, assessing the diversity in local cultures and comparing them with others is known to contribute to the individuals' cultural identity, harmony, and peace within a society that hosts these diverse cultures (Byram, Gribkova \& Starkey, 2002). In this sense, targeted cross-cultural learning aims to make students aware of their own culture and sustain their socialization while promoting their interpersonal relationships with people from different cultures (Banks et al., 2001). For this, obviously it will be crucial that teachers maintain diverse and interconnected proficiencies to respond to students' needs in what is, in the same token, constantly diversifying educational contexts, and to cope with the difficulties the latter face. The European Commissions' Directorate-General for Education, Youth, Sport and Culture (2017) has highlighted in its final report that there is an empirical research gap within literature focusing on diversity in teachers' preparatory environment. 
This is another indicator of how important it is to have thorough training for teachers. In the long term and as the benefits start to trickle down the line of education, the consequence of such an effort - fairly inferring - is that cross-cultural learning can potentially contribute to the development of society as a whole.

In light of such awareness, the current study examines the scope and the dimensions of culture and cross-cultural competency while aiming to improve cross-cultural competency. Within the scope of this research, the cultural background of Turkish language teacher candidates studying at one of the universities in Ankara, Turkey is examined along with their cultural competency capabilities by means of learning materials developed by them for the present research. The results are evaluated within the scope of the candidates' cross-cultural competency capabilities, and all the related concepts are presented from a holistic perspective.

\subsection{Culture and Language Teaching}

Initially, to present a clear conceptual framework for this research, one has to define what 'culture' means; it is defined as the way of life, especially the general customs and beliefs, of a particular group of people at a particular time. However, culture is not limited to lifestyle, general customs, and beliefs alone, and it involves numerous attitudinal, behavioral, and changeable aspects such as values, norms, and understandings. According to Kramsch (1998), culture implies fixed systems that contain common worldviews such as perceptions, beliefs, evaluations, and actions. A more comprehensive definition for culture is "the set of attitudes, values, beliefs, and behaviors shared by a group of people, but different for each individual, communicated from one generation to the next" (Matsumoto, 1996, p. 16). Among the various definitions of culture, many concepts emerge, namely language, food, appearance, communication style, beliefs, values, attitudes, and perceptions. On top of all these, subjective and evaluative factors contribute further to the notion of diversity in a given culture. Brislin $(1990, \mathrm{p}$. 11) highlights the implicit and unconscious acts of culture by stating that it "refers to widely shared ideals, values, formation, and uses of categories, assumptions about life, and goal-directed activities that become unconsciously or subconsciously accepted as 'right' and 'correct' by people who identify themselves as members of a society." (as cited in Kramsch, 1998, p. 2). The definition of culture, which focuses on functionality for humans, belongs to Garcia (1982, p.7): "a system of beliefs, values, customs, and institutions that when combined serves as a cluster to provide a person meaningful ways for survival." Also, Garcia (1982) explains culture from a functional perspective because, in Garcia's definition of culture, the content and component of culture does not necessarily mean collective commodities or experiences. Based on that functional perspective, culture is defined as: “...having discrete elements .... as a process that functions at varying levels of explicit and implicit realities. .... as a process that is learned and taught. ... as a process of shared gratification."

Discussing the various definitions of culture is beyond the scope of the current research. For the purposes herein, culture is not confined to a particular definition, but it is accepted from pragmatic and practical perspectives to adopt culture as an umbrella term. With this in mind, it can be stated that all shared spaces, classroom environments, and societies of different sizes could potentially shelter diverse cultures. Although the members of a society share the same language, there are many differences in their way of thinking, speaking, and behaving, leading to no particular unity among them. Those differences vary depending on the members' background, education, and socioeconomic status. In addition to these factors, attitudes within the family, values, lifestyles, language, religious beliefs, ethnicity, and nationality also contribute to these differences. As Hofstede \& Hofstede (2005) assert, almost everyone simultaneously belongs to a number of different subgroups which correspond to different levels of culture. Therefore, for cultural and cross-cultural learning which result in improvement of linguistic and societal development, the issue of diversity has to be considered thoroughly. According to Hall (1976), understanding the reality of the culture adopted by individuals is not a rapid process because cultural learning is not limited to reading or deductions, but also experiencing. Therefore, cultural learning, which requires special effort and experience, needs to be programmed and structured - for which ultimate goal, formal education appears to be ideal as it helps learners, through proper and deliberate methods, to acquire their cultural identity compatible with the rest of their society's identities. As the protagonists of formal education, teachers have crucial tasks at this point, particularly language teachers since language is one of the factors that makes culture distinct. In other words, because of the mediatory role of language in culture, cultural learning can be considered as a matter-of-fact concern among those who teach it. Also, culture is "often considered to be a fifth skill, after speaking, listening, reading, and writing" (Kramsch, 1996, p. 87), and it indicates that one of the primary goals of learning a new language is the acquisition of the culture. If culture is an essential aspect of language teaching, then language teachers can be expected to have a considerable impact on students as they can promote cultural information and cross-cultural understanding. 


\subsection{The Scope and the Dimensions of the Culture}

The concepts used to define culture also outline its content, within which there are hints of information about beliefs, customs, attitudes, norms, social implementations, values, and behaviors, not to mention the elements of civilization. However, being such a broad term makes culture challenging to assess, conceptualize, and classify. Naturally, this difficulty also manifests itself in cultural teaching and causes creates numerous hurdles when setting goals for teaching purposes. The first theory that clarified these challenges was presented by Edward T. Hall (1976), who stated that culture is of hidden and visible nature. Weaver (1986) clarifies this theory by using the iceberg analogy, in which surface culture is depicted as the tip of the iceberg as the surface disguising the depth. In detail, surface culture is the tip of the iceberg, and deep culture, which refers to beliefs, values and thought patterns, is submerged and, hence, invisible. In a society, deep culture has a bigger share than the surface culture. Garcia (1982) indicates that the culture of a particular group has two levels, explicit and implicit. Accordingly, while explicit culture contains standardized behavioral patterns, reactions, and affections, implicit culture includes hidden, implicit, subtle values, attitudes, and assumptions. The classification of culture made by Hall (1976), Garcia (1982), and Weaver (1986) shed light on understanding the different levels associated with culture. At this stage, to clarify the relationship between the previously mentioned theories of culture and language teaching, it is essential to mention some views that highlight which aspects of cultural competency should be assessed in language teaching. Four extensive perspectives have been introduced on what aspects of culture are suitable for students that learn language during their education (Crozet \& Liddicoat, 2000; Crozet et al., 1999; as cited in Liddicoat, 2004): high culture, area studies, culture as societal norms, culture as practice. High culture is the most traditional approach for culture education during the process of language teaching, and it concerns the transference of the universal culture. Next, the area studies' view of culture perceives cultural learning as the process of acquiring knowledge on the history, geography, and institutions of the country hosting the target language. According to this view, having area knowledge provides background information for understanding the language and the society. According to the third view, culture as societal norms, cultural competency predicts the behavior of the members of the focused society, understands their behaviors, or recognizes their cultural values in the context of their particular beliefs. In this view, cultures are defined in the context of representative practices and values. Lastly, in culture as practice, it is perceived as the experiences of individuals. Based on this view, "the target for the language learner is to develop an intercultural perspective in which the native culture and language are made apparent alongside the target culture (Liddicoat, 2004, p. 299-300)." The current studies on the cultural component in language teaching mostly tend to focus on culture as a practice, implying that it is no longer valid to apply cross-cultural learning in the context of second/foreign language teaching and in programs which focus on only teaching the culture of the target language. Therefore, while addressing the issue of cultural competency, it becomes vital to compare the target language with the local culture and provide a solid base for cross-cultural understanding. Besides, regarding the definition for culture as a practice, cross-cultural learning is not fulfilled when the subject matter is not addressed adequately. Considering this, focusing on the fact that culture is fluid, diverse, unifying, and functional for communication is necessary to designate cultural competency factors in a cross-cultural education context.

\subsection{The Framework of Cross-cultural Competency}

As previously stated, outlying a framework for cultural competency is challenging because culture is an umbrella term, contains contradictory levels, and is a subjective and fluid concept. In addition, targeting the concepts of culture necessary to teach is a complicated process with no clear-cut guideline. Nevertheless, experts have presented a set of criteria and frameworks to this end. Mainly, there are four agreed-upon components of cross-cultural competency (Knapp-Potthoff 1997; as cited in Thije \& Robert Maier, 2012, p. 635): "(1) knowledge of language and culture, (2) insight in general communicative principles, (3) strategies of interaction for engaging in intercultural situations and (4) (cap)abilities to learn in and through intercultural situations." These highlight the need for information transference and the applied methods during cross-cultural learning. While the third component refers to active engagement, the fourth one emphasizes the comparative and experimental aspects of cross-cultural competency. It is important to note that experience has an important place in the process of cross-cultural learning. Tsang (2020) shows that the students' previous cross-cultural experiences can significantly predict both their behavior and their views. Furthermore, Hall (1976) indicates that experiencing the shared and repetitive aspects of culture is essential for interactions among society members. According to these two views, the primary indicator of cross-cultural competency is interaction with people from different cultures. To achieve this more constructively, acquiring experience related to cross-cultural settings can be fulfilled. However, being present or living in different cultural environments might not be enough to acquire cross-cultural experience; there are other requirements to develop cross-cultural competency, namely appropriate environment, and structured and deliberate tasks. Seelye 
(1993), an eminent researcher on the current topic, describes the main goal of cross-cultural competency as a multitude of abilities to comprehend, perform, and develop attitudes to interact with individuals from other cultures. The main goal of cross-cultural competency indicated by Seelye, in this way, emphasizes the abilities required for interaction. This view is also compatible with the conceptualization of culture as a practice. Besides, Seelye (1993, p. 31) outlines six goals that are parallel to the afore-mentioned main goal of cross-cultural competency:

1. Interest: The student shows curiosity about another culture (or another segment or subculture of one's own culture) and empathy toward its members.

2. Who: The student recognizes that role expectations and other social variables such as age, sex, social class, religion, ethnicity, and place of residence affect the way people speak and behave.

3. What: The student realizes that effective communication requires discovering the culturally conditioned images that are evoked in the minds of people when they think, act, and react to the World around them.

4. Where and when: The student recognizes that situational variables and convention shape behavior in important ways.

5. Why: The student understands that people generally act the way they do because they are using options their society allows for satisfying basic physical and pychological needs, and that cultural patterns are interrelated and tend mutually to support need satisfaction.

6. Exploration: The student can evaluate a generalization about the target culture in terms of the amount of evidence substantiating it, and has the skills needed to locate and organize information about the target culture from the library, the mass media, people, and personal observation.

The goals outlined by Seelye (1993) pave the way toward supporting tasks that help raise the students' cross-cultural awareness. What is more, these goals do not merely focus on the culture's association with language, but also on the implicit and deep levels of culture - a framework compatible with Hall's (1976), who stated that assessing culture through the context of language is a narrow view because communication is not limited to language alone and involves various methods.

Considering that cross-cultural competency is not a process that can be achieved immediately, Ting-Toomey (2007) states that one of the constructive methods for developing students' capabilities and communication skills is by providing cross-cultural education. Zhang suggests the following as reference to cross-cultural learning:

1. To develop cross-cultural sensitivity, and awareness, learning to look at, analyze, and resolve problems from the perspective of cultural differences.

2. To cultivate cross-cultural attitudes, which include being tolerant, respectful, curious, and empathetic towards other cultures.

3. To acquire cultural knowledge, both culture general and culture specific, paying special attention to the invisible cultural elements, which are like the hidden part of an iceberg.

4. The ultimate goal of cross-cultural learning is to transform our awareness, attitudes, and knowledge into competence, and to develop flexibility and adaptability in cross-cultural communication. (Futurelearn, 2021)

These goals focus on several aspects, such as acquiring information about diverse cultures, ability to address surface and deep levels of culture, and comparing/contrasting different cultures. Nevertheless, such acquisitions might prove to be beyond the capability of individuals attempting to use them on their own and without instructional assistance. In addition, as development of cross-cultural competency affects human traits - respect, patience, tolerance, and humbleness to mention a few (Khan-Panni \& Swallow, 2003) - it should be handled as a separate subject in teacher's preparatory programs.

\section{Method}

\subsection{Participants}

The participants are 61 (45 female, 16 male) as Turkish language teacher candidates studying at a state university (Ankara, Turkey) in 2020 at the time of conducting the present research. The content of the classes taught in the Turkish language teacher training program at this university was carefully examined to see if the participants have 
received any classes related to culture/cross-cultural learning that might confound the results. Only one course, named "Culture and Language", met the criteria, though elective. Among 61 participants, 25 of them had already taken this course.

\subsection{Materials}

First, the participants received an e-mail asking whether they had taken the "Culture and Language" course. To assess the cross-cultural awareness of the participants, the researcher asked them to design a learning material. The participants were provided with three instructions about the outline of the material:

1) The material should focus on "developing cross-cultural competency in students";

2) The material should target students above 12 years of age living outside Turkey, and it should support their cross-cultural competency; and

3) The design of the material is up to the participants, implying freedom in devising the lecture, choosing the cultures and including any activity/visual aid.

4) The material is intended for a 40-minute lesson. Thus, the participants were asked to limit the learning materials between 3 and 10 pages and complete the task within three weeks. The instructions were sent via e-mail by the researcher, who is also the instructor of the elective course "Teaching Turkish Language to Bilingual Turkish Children". During the 3-week period, the instructor answered the participants' questions via e-mail while ensuring minimum assistance on the assigned task.

\subsection{Data Collection and Analysis}

Almost all participants (59 out of 61) returned their learning materials in time via e-mail. The content of the materials in the context of cross-cultural aspects was analyzed. Accordingly, the data were classified into twelve categories using thematic analysis: 1) traditions and customs; 2) food culture; 3) apparel; 4) literature; 5) religion; 6) history; 7) family; 8) community culture; 9) local festivals and celebrations; 10) gaming and entertainment culture (the entertainment or gaming activities of children and adults during their spare times); 11) art, music, dance; and 12) sports. All of the learning materials were coded according to the above-stated categories in order to outline the cross-cultural knowledge of the participants, and the data were analyzed. The learning materials were examined in terms of content they included and how it was presented.

\section{Results}

The learning materials developed by the participants were examined using thematic analysis, and the findings are explained below.

Among the fifty-nine learning materials, fifty-six met the inclusion criteria of the current study and, henceforth, categorized into groups as mentioned in the Methods section (see Figure 1); namely, 1) traditions and customs; 2) food culture; 3) apparel; 4) literature; 5) religion; 6) history; 7) family; 8) community culture; 9) local festivals and celebrations; 10) gaming and entertainment culture (the entertainment or gaming activities of children and adults during their spare times); 11) art, music, dance; and 12) sports. 


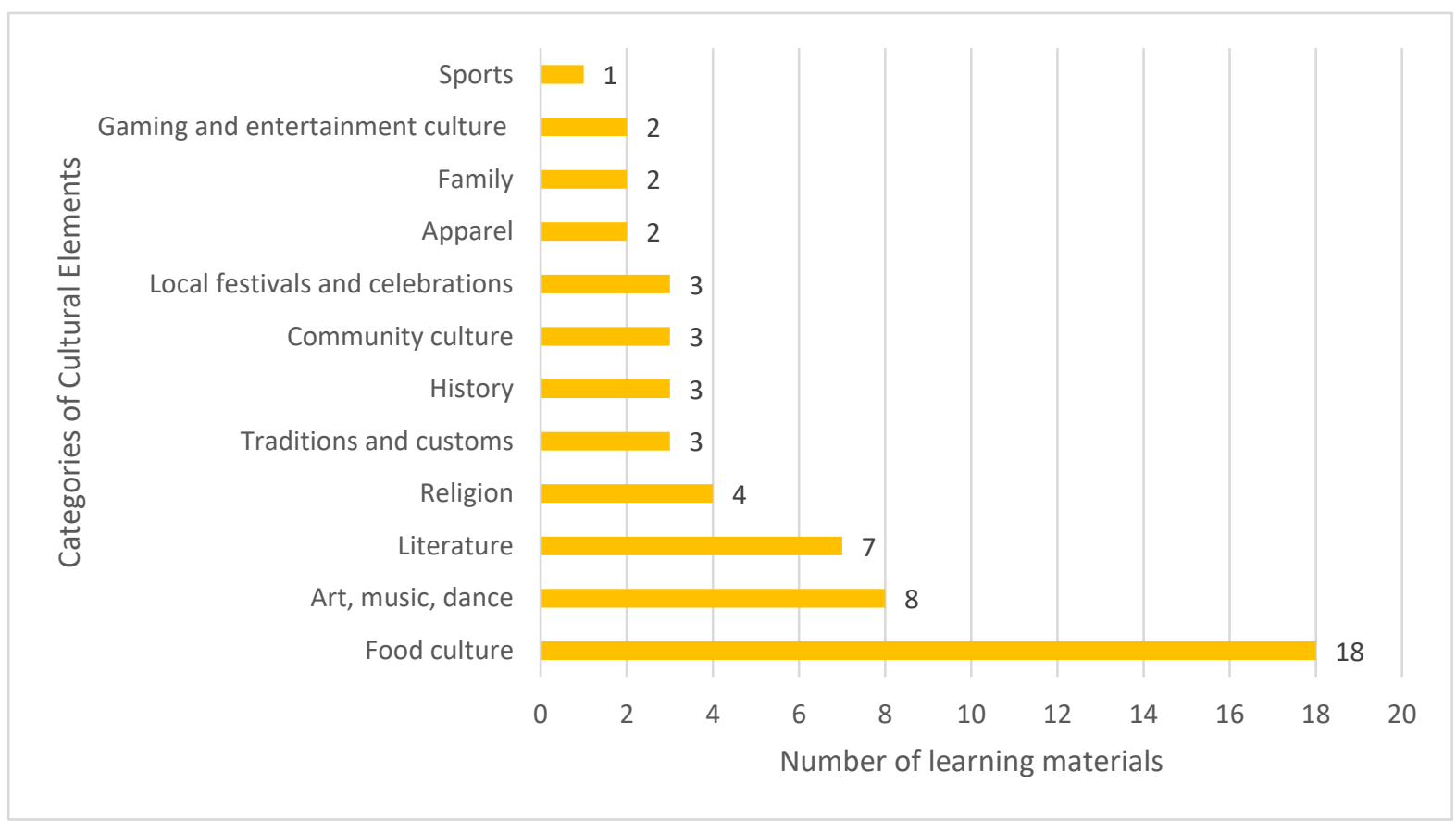

Figure 2. Column Chart for Categorical Classification of Learning Materials

The results showed how the participants approached the concepts of culture and cross-culturality and how they processed them (see Figure 2). On this basis, the most frequent category mentioned in the participants' learning materials was food culture (32\%), followed by art, music, and dance culture $(14 \%)$. The literature category $(13 \%)$ and religion (7\%) came after art, music, and dance culture. The rest included: traditions and customs (5\%), history $(5 \%)$, community culture, (5\%), local festivals and celebrations (5\%), apparel (4\%), family (4\%), gaming and entertainment culture (4\%), and sports $(2 \%)$.

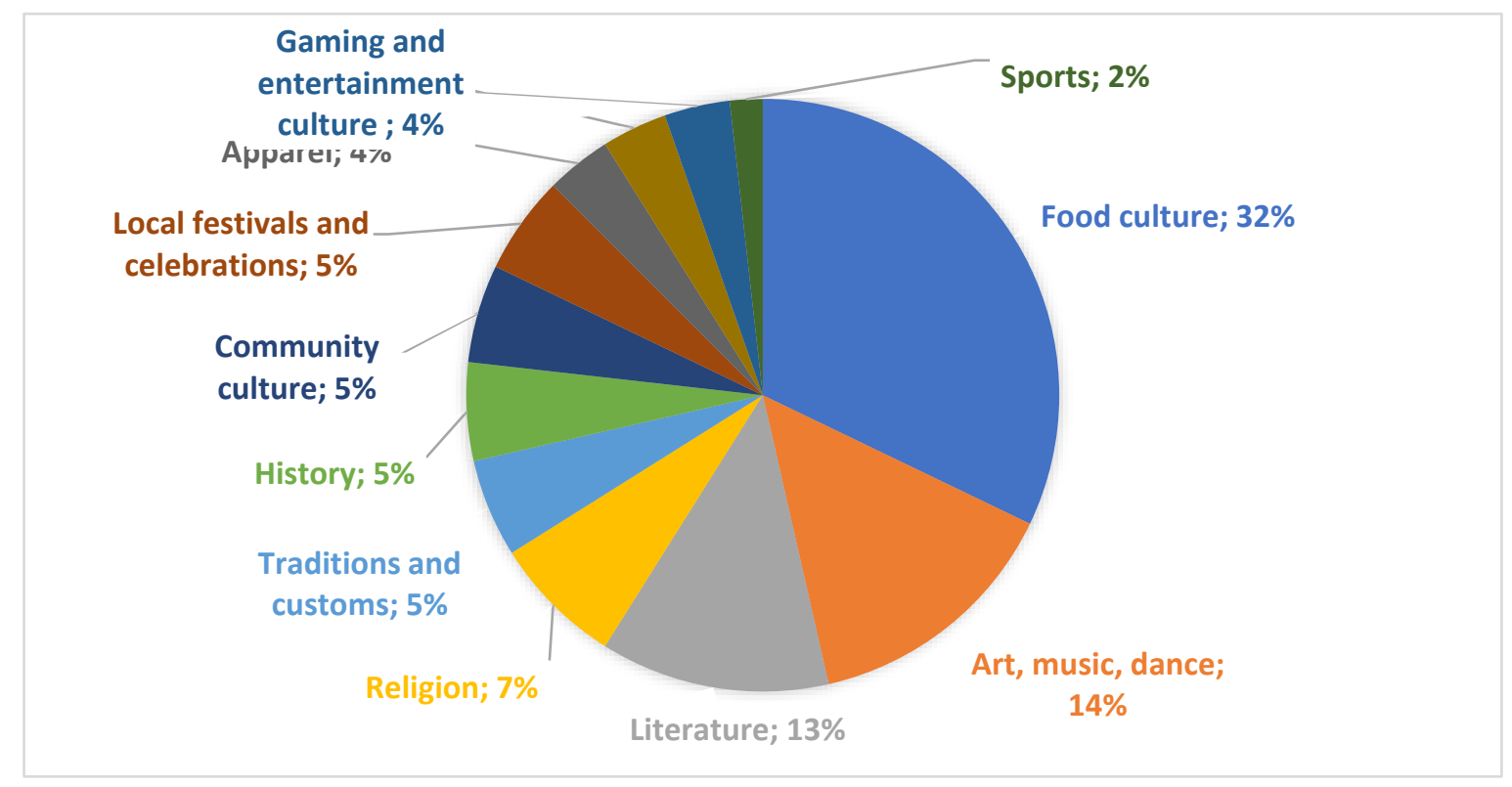

Figure 3. Pie Chart for Categorical Classification of Learning Materials 
Most of the designed materials involved cross-cultural comparisons. For example, one candidate working on prominent Turkish, Italian, Greek, and English food wrote the explanation for why those cultures had different foods under the title of "comparisons." The candidate also added to the learning material which type of Italian, Greek, and English food also belongs to the Turkish cuisine after explaining the diversity of food culture due to the country's geographic location, climate, and agriculture. That candidate referred to cross-cultural differences and similarities, so it can be seen that that particular candidate was able to generate cross-cultural comparisons.

Another teacher candidate developing material based on Indian and Turkish cuisines, compared the eating habits of the cultures and stated: "Ranjeet told us that all the dishes are served at the same time, but we (in Turkey) eat in an order starting from the soup to the dessert. They (Indians) do not follow an order as we do." Another candidate also focused on this subject included religion and tradition while presenting food and its relations to religious traditions. This candidate explained that "aşure" from the Turkish cuisine and "La Galette Des Rois" from the French were prepared on religious occasions. Based on these examples, one can deduce that a majority of the candidates incorporated cross-cultural comparisons into their learning materials.

Multiple cultural elements were intertwined in some of the learning materials. For example, a learning material targeting literature involved presenting Mevlana from the Turkish literature and Goethe from German to address their works' religious underpinnings. In some other learning materials, it was stated that religion was in the background of certain cultural events, traditions and festivals. For this, one candidate made an example of the Easter celebrated by Christians and the Feast of Ramadan celebrated by Muslims.

It was noteworthy that, of the participants, $42 \%$ had previously completed an elective class named "Culture and Language" in the Turkish language teacher preparation program, but none referred to deep or implicit aspects of culture in their learning materials. One conclusion to be drawn here is that the above-named course does not offer extensive focus on cultural dimensions and levels. In fact, when the respective course content is examined, the acquisitions of this class were said to be " defining the concept of culture, the sources of culture, the components of culture; analysing the importance of the relationship between language and culture; conducting critical evaluations on the texts about Turkish culture." However, in practice, the participants appeared to be incapable of planning supportive activities for cross-cultural competency. In addition, the syllabus of this class was limited to the dominant culture in Turkey, which is Turkish culture - a situation that might restrain individuals' ability to develop cross-cultural competency.

To enhance interaction with different cultures, which is an important indicator of cross-cultural competency, it is crucial to address the different aspects of those cultures affecting and supporting interaction. Among the participants, $9 \%$ (5 participants) referred to deep or implicit aspects of culture in their learning materials. One of the teacher candidates compared and contrasted greetings and farewells in Turkish and Finnish cultures and gave information about etiquettes - a deep aspect of culture - in the sample material. Also, this teacher candidate wrote how important it was for Finns to have eye contact during a conversation. On the same topic, another candidate referred to the salutation expressions in the Turkish and German cultures while adding some Turkish expressions that have no equivalents in German:

\section{There are some frequently used linguistic expression templates in Turkish which are utilized during salutations even though they do not directly imply any greeting, such as 'kolay gelsin' (more power to you/may it be easy), 'hayirl işler' (have a nice working day) or 'bereketli olsun' (may it be plentiful - said for a fieldwork) and there are no exact words for them in German, so those Turkish words would not be understood in an cross-cultural interaction.}

In the classification made by Weaver (1986), "[v]arious discourse templates in different contexts" is a deep aspect of culture. The learning material mentioned above involves an element that belongs to the deep aspects of culture. The remaining three candidates referred to relations with neighbours, female-male relations, and kin relations in their sample materials in the context of the deep aspect of culture. Knowing these aspects could increase the ability to improve cross-cultural capabilities of others because the elements belong to the deep aspects of culture (e.g., values, attitudes, lifestyles; the roles related to age, gender, social class, kinship, vocation, and religion; the concept of belief) shape the human behaviour. Regarding the need to tackle the deep aspects of culture that have a supporting role in communication during cross-cultural learning, the teacher candidates participating in this study appear to lack the necessary qualifications.

Among the fifty-nine teacher candidates who participated in the current research, three did not refer to cross-cultural comparisons at all, thus their exclusion. In the fifty-six learning materials, most participants highlighted the similarities and dissimilarities of multiple cultures. This shows that they are aware that it is important to compare 
different cultures to make the student develop cross-cultural competency. Another notable finding is that participants did not include their own culture (Turkish) as much in the learning materials, focusing instead on presenting to the students the target culture in an equal and objective manner. Nor did they project a judgmental approach while addressing other cultures. Accepting all as equal is a fundamental principle for improving cultural awareness (Vaudrin-Charette, 2019), the teacher candidates in the current study demonstrate a manner that reflects their cross-cultural awareness. Another remarkable finding is that the candidates did not propose any activity that focused on exposing students to an cross-cultural experience. Regarding the importance of acquiring experience for communicating with people from different cultures, the candidates are, once again, found to lack the requirements. To sum up, as an overall assessment, it can be stated that the teacher candidates enrolled in the Turkish language teacher preparation program studied in the present research need to improve their qualifications to assist their prospective learners in acquiring cross-cultural competency during language education.

\section{Discussion}

While societies continue to become more diverse, education continues to maintain its role in providing adaptation for the students to the novel realities of their surrounding society and the world. In globalized terms, education has many current roles, primarily helping students understand cultural diversity, respecting it fully, and analyzing it objectively. Education should also guide the students to cooperate and communicate with people from different cultures in an open-minded and tolerant way (Cocoş, 2015). In order to materialize these acquisitions, enhancing their cross-cultural competency capabilities is an important factor not limited to information exchange or providing accumulated intellectual knowledge, but embracing other aspects and doing so in a more practical and real-world sense. Discovering the alternative pathways and views among different cultural practices, beside cultivating cultural knowledge, is an important vehicle along the way from cultural sensitivity to cross-cultural competency. Transference of cultural knowledge is at the base of cross-cultural learning. However, presenting culture as mostly definitional, static, superficial, and narrow might not be adequate for developing cross-cultural education in language teaching. Teaching culture to diversify the content of language classes without setting goals does not prepare the students satisfactorily for a world with diverse cultures (Nault, 2006). Students should understand the targeted cultures, as the root of behavior and the supporting factor for interpersonal interaction in a dynamic way. Moreover, they need to possess a deep and humanitarian sense to attach meaning to diverse cultures while dealing with their diversities. Similarly, Holliday (2016) argues that intercultural competence is a continuous activity which starts from birth and develops by socialization. Therefore, approaches targeting stable dimensions can potentially be in sufficient for intercultural learning. According to Drewelow and Mitchell (2015), when cultural learning does not create a space for cultural contacts and contradicting views, such an approach toward cultural learning simply turns into nothing but a "touristic communication."

With this in mind, concerning the samples of lectures created by the participants of this research, it was observed that most candidates focused on presenting the same "touristic" aspect of culture. This situation points to a problematic issue associated with critical thinking methods in teaching either the local culture or a foreign one. In language teaching, it is appropriate to find a balance between goals related to linguistic/communication and goals related to cross-cultural knowledge/capabilities. Due to the variable nature of culture, an interactive teaching which allows continuos explorations can be designed rather than a cognitive and abstract one. As a result, the Council of Europe (2001) set up a series of goals related to linguistics, communication, and the superficial aspects of culture and its deep levels in the CEFR (Common European Framework of Reference for Languages). Also, it suggests goals targeting the understanding of cultural similarities and dissimilarities while embracing them. These goals are directed toward fulfilling the current needs of education, thus requiring comprehensive approaches to culture.

Based on the classifications proposed by Hall (1976), Garcia (1982), and Weaver (1986), observable factors (e.g., language, art, literature, religions, music, apparel, dance, festivals, games, sports, and food), along with deliberate acts, represent surface culture. In this vein, the current study finds that a vast majority of the participants focused more on the elements of surface culture and presented a static view of culture as a concrete representation in their learning materials. In the static view of culture, students are required to "learn information about a country or people, their lives, their history, their institutions or their customs or about the cultural icons these people have produced, such as their literature, their art, their architecture or their music." (Liddicoat, 2004, p. 301). However, according to Paige et al. (1999),

This approach to culture is problematic for language teaching because it omits key elements of cultural knowledge which are important for intercultural communication, such as underlying value systems, 
cultural variability within target language communities, the role of the individual as a creator and enactor of culture and the ways in which language and culture interact in the creation of meaning." (as cited in Liddicoat, 2004, p. 301).

Weaver (1986) highlights that the surface view of culture represents a lesser proportion of culture than deep culture does. Therefore, learning only from this surface perspective could lead to many more aspects to remain unlearnt. Considering the limiting, but also enabling, human action nature of culture, it can be asserted that merely learning surface-based static culture and its elements would not be sufficient for providing a base for understanding human behavior in its full scope. Providing information about a culture might be an important tool for reducing stereotyping, but this approach would be insufficient for explaining cultural diversity and culture-building (Crawford- Lange \& Lange, 1984; as cited in Sehlaoui, 2001).

Another effect of this approach is that it cannot sufficiently provide cross-cultural competency because the latter refers to how people adapt their thoughts and behaviors according to changing cultural environments (Kim, 1988). Learning the components of culture from the surface view is questionable regarding thoughts and behaviors' change. Having a narrow perspective when conceptualizing culture might also limit the understanding of diverse cultures and their multiple layers. Sehlaoui (2001) claims that defining cultural diversity in the limits of ethnicity or nationality hinders focusing on more prevalent and distinctive differences such as social class and gender, instead suggesting that aspects of culture such as sociopolitical context, interactions between individual and social entities should be taken into consideration while critically understanding the overall impact of those concepts. "In order to improve our cross-cultural interactions, teachers must learn not just the basic facts but even important nuances of their students' cultures (Hodgkinson, 1991; as cited in Pratt-Johnson, 2006)."

When data is evaluated based on the produced learning materials and through the viewpoints mentioned here, one highlights the need for the participants to understand the multilayers of culture alongside its complex and fluid nature. In all, the Turkish language teacher candidates should initially attempt to build a more extensive cultural base, followed by cross-cultural competency to be promoted through their learning materials among the learners.

\section{Conclusion}

The concept of cross-culturality continues to be the focus of academic and vocational societies. This interest might be due to three reasons. First, the need for effective communication in a foreign language has increased due to globalization and migration. Second, the need for understanding different cultures within a society and living in harmony in environments with cultural diversity has emerged. Third, "[c]ultural awareness will bring teachers and students closer together, and subsequently assist in overcoming language barriers and addressing identified gaps in academic skills (Willis, 2021, p.15)". These reasons have led education decision-makers and other stakeholders to reconsider the capabilities of the teachers as agents of education. As Kramsch (2004) puts it, "teachers have a crucial role to play as practitioners between academic disciplines, as mediators between generations and social classes, as catalysts between conflicting worldviews, as navigators between the demands of the institution that pays them and the needs of the world they envisage for the future (p. 57)".

The current study shows that the participant enrolled in the language teacher preparation program examined here lack cross-cultural knowledge and awareness. Without such capabilities, the students they are likely to teach in future might not receive the proper cultural awareness they are supposed to according to their curricula. To make up for this significant gap, courses need to be added to training programs that target improving the candidates' cross-cultural competency with applied methodology. Developing cross-cultural competency is directly associated with cultural learning. This means that teachers cannot be regarded intrinsically well-equipped with cross-cultural competency, particularly when it comes to complex, extensive, and fluid aspects. Cultural learning is the fundamental component of acquiring cross-cultural competency; therefore, training in this respect should be integrated systematically and extensively into the programs designed to this end. In this respect, the cross-cultural learning standards developed by Seeberg ve Minick (2012) would provide a fundamental framework for those interested.

Cultural learning is more effective and motivating when students acquire information about their belief systems, values, and traditions and then systematically make connections between their culture and the target cultures (Mantle-Bromley 1995; as cited in Abrams, 2002). Another issue is that, while making policies about language teaching, candidates should be considered as a whole, not separate entities as foreign and native language teachers because culture is closely linked with linguistics. In either case, learning and teaching programs that target enhancing cross-cultural competency should perceive the two groups as one, for whom "Culture teaching approaches should 
move from the descriptive to the interactionists, fostering interactions and discussion leading to self-awareness, openness, and transformation." (López-Rochas, 2016, p. 109). Lastly, it will be beneficial to focus on aspects of culture related to linguistic and communications such as fluidity, presentation of similarities and dissimilarities, mediation, holistic aspects, and usefulness for interaction.

\section{References}

Abrams, Z. (2002). Surfing to Cross-Cultural Awareness: Using Internet-Mediated Projects to Explore Cultural Stereotypes. Foreign Language Annals, 35, 141-160. https://doi.org/10.1111/j.1944-9720.2002.tb03151.x

Banks, J. A., Cookson, P., Gay, G., Hawley, W. D., Irvine, J. J., Nieto, S., et al. (2001). Diversity within unity: Essential principles for teaching and learning in a multicultural society. Phi Delta Kappan, 83(3), 196-202. https://doi.org/10.1177/003172170108300309

Byram, M., Gribkova, B., \& Starkey, H. (2002). Developing the Intercultural Dimension in Language Teaching: A Practical Introduction for Teachers. Strasbourg: Council of Europe. https://doi.org/10.21832/9781853595356-002

Cocoş, Elena. (2015). Education, Cultural and Intercultural Relation. Procedia - Social and Behavioral Sciences. 180 , 36-41. https://doi.org/10.1016/j.sbspro.2015.02.082

Council of Europe. (2001). Common European framework of reference for languages. Cambridge: University Press.

Drewelow, I., \& Mitchell, C. (2015). An exploration of learners' conceptions of language, culture, and learning in advanced-level Spanish courses. Language, Culture and Curriculum, 28(3), 243-256, https://doi.org/10.1080/07908318.2015.1078347

European Commission. (2017). Preparing teachers for diversity: the role of initial teacher education: Final Report. Retrieved https://op.europa.eu/en/publication-detail/-/publication/b347bf7d-1db1-11e7-aeb3-01aa75ed71a1

Futurelearn (2021). Highlighting goals of intercultural learning. Retrieved from https://www.futurelearn.com/info/courses/intercultural-communication/0/steps/11045

Garcia, R. L. (1982). Teaching in a pluralistic society: Concepts, models, strategies. New York: Harper \& Row.

Hall, E. T. (1976). Beyond culture. New York: Anchor Books.

Hofstede, G., \& Hofstede, G. (2005). Cultures and organizations: software of the mind: intercultural cooperation and its importance for survival. McGraw-Hill: New York.

Holliday, A. (2016). Revisiting Intercultural Competence: Small Culture Formation on the Go through Threads of Experience. International Journal of Bias, Identity and Diversities in Education, 1(2), 1-14. https://doi.org/10.4018/IJBIDE.2016070101

Khan-Panni, P., \& Swallow, D. (2003). Communicating across cultures. The key to successful international business communication, Howtobooks, Oxford.

Kim, Y. Y. (1988). Intercommunication series, 2. Communication and cross-cultural adaptation: An integrative theory. Multilingual Matters.

Kramsch, C. (1996). The cultural component of language teaching. Language, Culture and Curriculum, 8(2), 83-92. https://doi.org/10.1080/07908319509525192

Kramsch, C. (2004). The language teacher as go-between. Utbildning \& Demokrati, 13(3), 37-60. https://doi.org/10.48059/uod.v13i3.781

Kramsch, C. J. (1998). Language and Culture. Oxford: Oxford University Press.

Liddicoat, A. J. (2004) The Conceptualisation of the Cultural Component of Language Teaching in Australian Language. Education Policy, Journal of Multilingual and Multicultural Development, 25(4), 297-317. https://doi.org/10.1080/01434630408666534

López-Rocha, S. (2016). Intercultural communicative competence: creating awareness and promoting skills in the language classroom. In C. Goria, O. Speicher, \& S. Stollhans (Eds.), Innovative language teaching and learning at university: enhancing participation and collaboration (pp. 105-111). Dublin: Research-publishing.net. https://doi.org/10.14705/rpnet.2016.000411 
Matsumoto, D. (1996). Culture and Psychology. Pacific Grove, CA: Brooks/Cole.

Nault, D. (2006). Going Global: Rethinking Culture Teaching in ELT Contexts. Language, Culture and Curriculum, 19(3), 314-328. https://doi.org/10.1080/07908310608668770

Pratt-Johnson, Y. (2006). Communicating Cross-Culturally: What Teachers Should Know. The Internet TESL Journal, XII(2). Retrieved from http://iteslj.org/Articles/Pratt-Johnson-CrossCultural.html

Seeberg, V., \& Minick, T. (2012). Enhancing Cross-cultural Competence in Multicultural Teacher Education: Transformation in Global Learning. International Journal of Multicultural Education, 14(3). https://doi.org/10.18251/ijme.v14i3.569

Seelye, H. N. (1993). Teaching Culture: Strategies for Intercultural Communication. Lincolnwood IL: National Textbook Company.

Sehlaoui, A. S. (2001). Developing Cross-cultural Communicative Competence in Pre-service ESL/EFL Teachers: A Critical Perspective. Language Culture and Curriculum, 14(1), 42-57, https://doi.org/10.1080/07908310108666611

Thije, J. Den \& Maier, R. (2012). Managing cultural and linguistic diversity in multiple organisational settings: editorial, Journal of Multilingual and Multicultural Development, 33(7), 629-641. https://doi.org/10.1080/01434632.2012.713960

Ting-Toomey, S. (2007). Intercultural conflict training: Theory-practice approaches and research challenges. Journal of Intercultural Communication Research, 36(3), 255-71. https://doi.org/10.1080/17475750701737199

Tsang, A. (2020). Examining the relationship between language and cross-cultural encounters: avenues for promoting intercultural interaction. Journal of Multilingual and Multicultural Development, https://doi.org/10.1080/01434632.2020.1725526

Vaudrin-Charette. (2019). Melting the Cultural Iceberg in Indigenizing Higher Education: Shifts to Accountability in Times of Reconciliation. New Directions for Teaching and Learning, 2019(157), 105-118. https://doi.org/10.1002/tl.20333

Weaver, G. R. (1986). Understanding and coping with cross-cultural adjustment stress. In: Paige, R. M. (Ed.), Cross-Cultural Orientation: New Conceptualizations and Applications. Lanham, MD: University Press of America, pp.111-145.

Willis, A. S. (2021). Teachers' cultural, social and emotional capabilities: how teacher compassion and humility is an antecedent to student confidence. Pedagogy, Culture \& Society. https://doi.org/10.1080/14681366.2021.1884122

\section{Copyrights}

Copyright for this article is retained by the author(s), with first publication rights granted to the journal.

This is an open-access article distributed under the terms and conditions of the Creative Commons Attribution license (http://creativecommons.org/licenses/by/4.0/). 